\title{
Does exposure to inhalational anesthesia early in life cause brain damage?
}

\author{
Richard A. Jonas, MD
}

\footnotetext{
From the Department of Cardiac Surgery, Children's National Heart Institute, Children's National Medical Center, Washington, DC.

Disclosures: Author has nothing to disclose with regard to commercial support.

Received for publication April 4, 2016; accepted for publication April 5, 2016; available ahead of print May 6, 2016.

Address for reprints: Richard A. Jonas, MD, Children's National Medical Center, 111 Michigan Ave NW, Washington, DC 20010 (E-mail: rjonas@childrensnational.org).

J Thorac Cardiovasc Surg 2016;152:490

$0022-5223 / \$ 36.00$

Copyright $(2) 2016$ by The American Association for Thoracic Surgery

http://dx.doi.org/10.1016/j.jtcvs.2016.04.021
}

The article by Diaz and colleagues ${ }^{1}$ in this issue of The Journal adds further weight to the increasing concern that exposure of neonates and young infants to volatile inhalational anesthetic agents may affect their neurodevelopmental outcome. Diaz and colleagues ${ }^{1}$ have undertaken a meta-analysis of a subgroup of 96 patients with hypoplastic left heart syndrome who underwent neurodevelopmental testing as part of the previously reported apolipoprotein E trial conducted at Children's Hospital of Philadelphia between 1998 and 2003. Diaz and colleagues ${ }^{1}$ retrospectively collected information regarding exposure to volatile anesthetic agents, and their statisticians developed 4 models to test the hypothesis that cumulative duration of exposure to volatile anesthetic agents can influence full-scale IQ, verbal IQ, performance IQ, and processing speed at age 4 to 5 years. The hypothesis was confirmed for verbal IQ and full-scale IQ.

There are now a large number of animal studies as well as some early clinical studies that are building up the evidence that volatile anesthetic agents can have a deleterious impact on cerebral development when exposure occurs early in life. There are also some clinical studies, however, that have not supported this concept. Prospective clinical trials are currently underway. In the current retrospective report there are some important limitations, which Diaz and colleagues ${ }^{1}$ have conceded, particularly limitations regarding documentation of exposure to anesthetic agents in an era that predated automatic data recording in the operating room. There is also a problem in that the patient population underwent staged reconstruction for hypoplastic left heart syndrome. Not only is this group of patients at risk for prenatal effects of their abnormal in utero circulation, but in addition they all underwent additional cardiac or noncardiac procedures after their initial cardiac surgery. They also went through at least 1 or 2 critically important formative years with at least some degree of cyanosis.

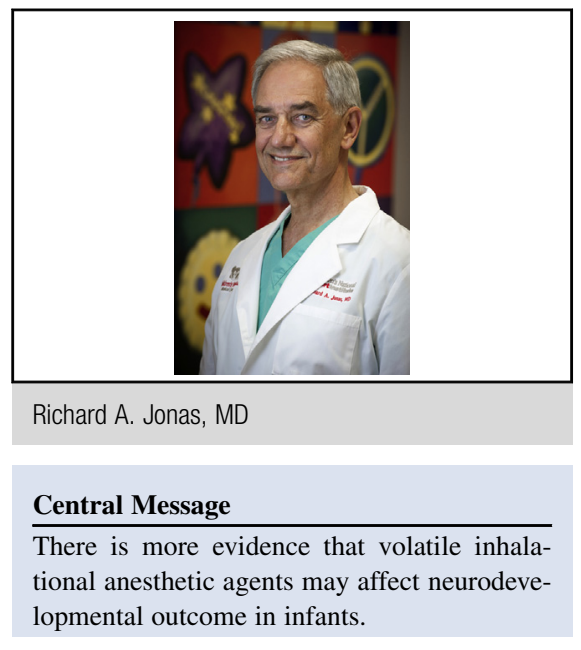

See Article page 482 .

Perhaps these factors help to explain the unusual finding that the statistical models do not identify socioeconomic status, maternal education, or ethnicity as predictors of neurodevelopmental outcome. In almost all previous studies of neurodevelopmental outcome in patients with congenital heart disease, these factors have been identified to be the strongest predictors of neurodevelopmental outcome.

Although Diaz and colleagues ${ }^{1}$ did not identify socioeconomic status, maternal education or ethnicity as predictors of neurodevelopmental outcome, they did find that intraoperative hematocrit was a predictor of both full-scale IQ and verbal IQ. This finding is consistent with the outcome of a large prospective trial of hematocrit.

In summary, Diaz and colleagues ${ }^{1}$ are to be congratulated on an important contribution that adds further evidence to the observation that volatile agents can affect neurodevelopmental outcome. It is clear that the time has been reached that a prospective randomized trial is indeed indicated, as stated by Diaz and colleagues ${ }^{1}$ in their conclusion.

\section{Reference}

1. Diaz LK, Gaynor JW, Koh SJ, Ittenbach RF, Gerdes M, Bernbaum JC, et al. Increasing cumulative exposure to volatile anesthetic agents is associated with poorer neurodevelopmental outcomes in children with hypoplastic left heart syndrome. J Thorac Cardiovasc Surg. 2016;152:482-9. 